\title{
The Policy and Institutional Challenges of Grid Integration of Renewable Energy in the Western United States
}

\author{
Authors \\ Angela Cifor ${ }^{1}$ \\ Paul Denholm ${ }^{2}$ \\ Erik Ela $^{2}$ \\ Bri-Mathias Hodge ${ }^{2}$ \\ Adam Reed ${ }^{1}$ \\ 1. University of Colorado-Boulder; 2. National Renewable Energy Laboratory
}

This work was supported by the U.S. Department of Energy under Contract No. DE-AC36-08GO28308 with the National Renewable Energy Laboratory. 


\begin{abstract}
Are organized markets necessary in the U.S. Western Interconnection for cost-optimal integration of renewable energy resources that, in accordance with state mandates, must be brought online in the coming decades? We examine the technological components of the western power grid as well as its political, institutional, economic, legal, and cultural attributes to assess the potential and feasibility of organized markets.
\end{abstract}

\title{
KEY WORDS
}

Renewable energy; electricity markets; renewable resource integration

\section{FUNDING STATEMENT}

This statement should be included in the published piece:

This work was supported by the U.S. Department of Energy under Contract No. DE-AC3608GO28308 with the National Renewable Energy Laboratory.

This statement provides additional information requested in author guidelines:

Staff of the National Renewable Energy Laboratory and the Joint Institute for Strategic Energy Analysis selected this work for funding through a competitive process, aided in design of the analysis, and evaluated the suitability of the writing and scholarship for publication. 


\section{INTRODUCTION}

Composed of diverse and largely independent organizational units and facing interesting technical challenges, the Western Interconnection power grid of the United States' electricity system must integrate increasing penetrations of variable renewable energy generation as required by various state laws providing for renewable portfolio standards (RPS) and encouraged by federal policies (such as the wind production tax credit) that aim to lower the costs of renewable power generation ${ }^{1}$. Integrating more renewable energy will likely require grid operators to procure increasing amounts of ancillary services that keep the grid running smoothly and reliably in the event of a failure on some portion of the system or, increasingly, a sudden, uncontrollable, weather-driven change in the output of renewable energy generators. As penetrations of renewable energy rise on the grid, the need for ancillary services and other grid modifications tends to increase as larger proportions of generation are subject to additional weather-driven uncertainty. Unlike in most of the Eastern Interconnection, where special markets allow both utility and independent generators to submit bids to the system operator for the opportunity to provide ancillary services at competitive market rates, the West continues to exhibit a distinct absence of organized markets, with the notable exceptions of California and Alberta. Western utilities typically procure ancillary services from their own systems, and do not always have access to the cost-savings and efficiency benefits that organized energy markets potentially offer. The result, presumably, is higher costs for system reliability overall as well as for the integration of renewable energy. The latter issue is the focus of this paper, as renewable generators often bear the sizeable financial brunt of integration costs even though they have little

\footnotetext{
${ }^{1}$ Abbreviations used in this paper: Western Electricity Coordinating Council (WECC); North American Electric Reliability Corporation (NERC); Federal Energy Regulatory Commission (FERC); independent system operator (ISO); energy imbalance market (EIM); regional transmission organization (RTO); Intra-hour Transaction Accelerator Platform (ITAP); the Dynamic Scheduling System (DSS); Balancing Authority Reliability-based Control (RBC); ACE Diversity Interchange (ADI).
} 
control over them (DeCesaro and Porter, 2009). The practical implication is that the current institutional organization of much of the West, including the absence of organized markets, limits the flexibility in the grid needed to integrate variable generation in the most cost-effective manner. As a whole, this tends to increase costs ultimately borne by ratepayers.

The West's electricity stakeholders, alongside its regional reliability organization, the Western Electricity Coordinating Council (WECC), have designed an array of creative solutions that attempt to address this problem, though they may fall short of integrating the large amounts of state-mandated renewable energy that must be brought online in the coming decades in a costoptimal manner. Accordingly, we are interested in two questions. First, do rising concerns about the costs of renewable energy integration suggest a pressing need for organized markets in the Western Interconnection? Second, how would such markets arise, and what are the barriers to their creation in the West?

Addressing these questions requires an analysis not only of the technological components of the western grid, but also its political, institutional, economic, legal, and cultural attributes. We undertook a year-long study of the problem, including a literature review at both the technical and policy levels; extensive confidential interviews with electric utilities, state and federal regulators, independent analysts, and energy system and renewables integration experts at the national laboratories; and observations of institutional and political dynamics at relevant meetings of the WECC, utility sub-groups, as well as the multi-state Public Utilities Commission Energy Imbalance Market Group meetings, which have centered attention around the possible creation of one or several regional energy markets for balancing energy. This paper collects our findings and observations (stripped of identifying information) and attempts to construct a coherent narrative of the Western Interconnection's historical relationship with the concept of 
organized markets and where policy may be headed. Our aim is to explain these issues clearly to legislative and regulatory decision-makers and their staff members so as to translate the concerns and insights of various technical experts, grid modelers, and utilities into a policy-level discussion.

This paper differs from the existing literature in terms of both focus and overall scope. Sovacool (2009) performed interviews with electricity system stakeholders and an extensive literature review on the impact of intermittent renewable generators on system reliability in the United States and posited that the main barriers to renewable integration were social, political, and historical. However, that analysis considered neither ancillary services nor the Western Interconnection specifically. Cappers, et al. (2013) reviewed market and policy barriers to allowing demand-response ancillary services in U.S. electricity markets, an oft-suggested means of aiding renewables integration. Interestingly, they identify changes in regional reliability councils' specific reliability definitions as a primary action needed to overcome barriers. However, even with these changes conflicting state policies and the strategic philosophies of individual utilities could still present a persistent barrier to both renewable energy integration and demand response adoption. Bohne (2011) explored the conflicts between different national regulatory cultures and the subsequent conflict within larger international energy regulations. While the work focuses on the EU and three of its member states, the different state paradigms described (enabling, providing, and ensuring) have analogs with the state policies encountered in the Western Interconnection.

We proceed in four parts. We first discuss the current state of the electricity system in the West, with an emphasis on the evolving legal and regulatory landscape. Second, we examine the expected additional requirements on the system with increasing rates of renewable energy 
penetration. Third, we address barriers, primarily institutional and cultural, to the development of solutions to meet these emerging needs. Finally, we describe a number of potential solutions, both market and non-market based, and explore where alternative paths might lead and projected environmental and economic outcomes.

\section{DISCUSSION \\ 2.1 STATE OF THE WECC}

WECC is the regional entity responsible for bulk power system reliability in the Western Interconnection. Geographically, it is the largest of the regional entities recognized by the North American Electric Reliability Corporation (NERC) and the Federal Energy Regulatory Commission (FERC), and includes all or part of 14 states, two Canadian provinces, and a portion of Baja California, Mexico. WECC consists of over 363 member institutions and serves compliance monitoring and enforcement, standards development, reliability coordination, and transmission planning functions for these members.

Ancillary services play a vital role in power system reliability and encompass many of the actions necessary to support the transmission of power from generators to consumers while ensuring reliable system operations. The manner in which ancillary services are named and defined varies greatly throughout the electricity industry. Ultimately, there is no uniform standard by which ancillary services are classified. For our purposes, we will adhere to the National Renewable Energy Laboratory's nomenclature when discussing ancillary services (Ela, et al., 2011). Some examples of these services include voltage and frequency control, scheduling, load-following, and system protection. Another class of ancillary service, operating reserves, includes generation capacity kept available in case of unexpected deviations from schedules or variability within a scheduling interval. Operating reserves are particularly relevant to the integration of increasing amounts of variable renewable energy onto the system, and are 
the primary focus here. Operating reserves can be classified according to the circumstance that triggers their deployment, the timescale of the response, and the direction of deployment.

A "following reserve" (often called a load-following reserve in practice) is a particular operating reserve that handles more sustained trends over a timescale of minutes. These reserves allow the power system to "follow" changes in load throughout the day. For example, a hot day will create additional electricity demand due to the need for more cooling in homes and businesses; system load will grow over the course of the afternoon and then recede later that night. Following reserves allow the system operator to match generation to this cycle on a subhourly basis. In organized energy markets, load-following is covered through real-time "balancing energy" markets run by the independent system operator (ISO). Some utilities operating in the West have proposed an Energy Imbalance Market (EIM) for the region to achieve the same goal, but deliberations are ongoing and it is unclear how many stakeholders will ultimately participate in a western EIM.

Organized energy markets, that is, those portions of the bulk power system run by an ISO or Regional Transmission Organization (RTO) ${ }^{2}$, provide for distinct dynamic markets for some of these ancillary services in addition to markets for energy commodities (see Figure 1). The FERC recognized a number of ancillary service types in its landmark Order 888 (1996), which was instrumental in the development of both open energy commodity markets and supporting ancillary service markets in the organized regions. Below we detail some of them, along with other commonly recognized ancillary services based on Ela, et al. (2012):

1. Scheduling, system control, and dispatch. This is the service that the ISO or RTO provides and is not applicable to our discussion of ancillary services market design.

\footnotetext{
${ }^{2}$ In 2000, FERC Order 2000 encouraged utilities to join RTOs, independently operated organizations that oversee transmission service and administer energy markets for a given region. RTOs and ISOs are often referred to as organized energy markets and are regulated by the FERC.
} 
2. Reactive supply and voltage control from generation service. Reactive power supply and voltage control is generally supplied as a cost-based service. By its nature, voltage control must originate close in proximity to its targeted use on the transmission system and is thus a poor candidate for competitive market procurement.

3. Regulation reserves and frequency response service. Today, regulation is typically supplied and priced by dynamic markets in ISO/RTO regions. It is used to assist in controlling frequency. Frequency response as defined by the "droop response" of on-generator governors autonomously responding to frequency dips, however, is generally not included in any dynamic markets; nor is it given cost-based rates or (at times) compensated at all.

4. Energy imbalance service. In organized ISO regions, open-access real-time markets procure balancing energy as needed to cover additional load not provided from day-ahead and hourahead scheduling in the so-called "forward" markets. Because balancing energy both supports the power system's delivery of energy (like an ancillary service) and is procured through actual energy markets (like other energy services), its classification among power engineers is inexact. It may or may not be classified as an ancillary service depending on the context.

5. Operating reserve-synchronized reserve service. This service, also called "spinning reserve," is typically supplied and priced by dynamic markets in ISO/RTO regions.

6. Operating reserve-supplemental reserve service. This service, also called "non-spinning reserve," is typically supplied and priced by dynamic markets in ISO/RTO regions. 


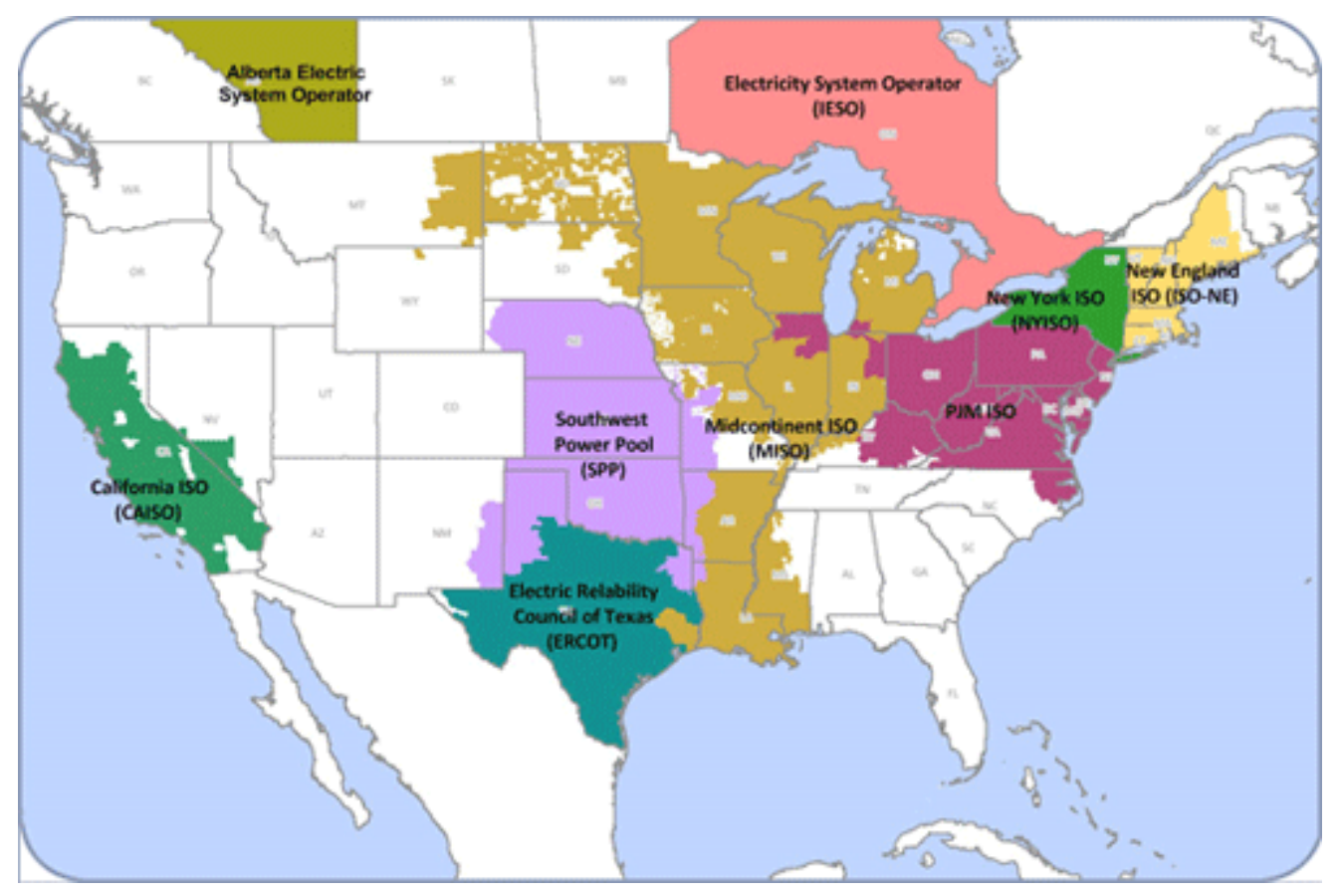

\section{Figure 1: ISO/RTO Regions in North America}

Clearing prices within existing ancillary service markets change as frequently as every five minutes. The open nature of the market allows any qualifying resource to bid competitively to provide service, and separate bidding processes occur for frequency regulation, spinning reserve, non-spinning reserve, and tertiary reserve. A resource providing ancillary services receives the market-clearing price, paid for by power consumers as part of the ISO's tariff for use of the transmission system. Power producers pass these costs through to their customers in the wholesale or retail markets.

The open architecture of ISO/RTO ancillary service markets provides transparency in prices to future suppliers of ancillary services, allowing service providers to invest in technologies other than conventional generation capacity, including demand-response and energy-storage capabilities. Generators may change operational patterns as well, forgoing energy sales in the real-time market in order to provide ancillary services that may result in greater revenue opportunities. Generators that engage in the sale of ancillary services may make 
moment-to-moment decisions as to whether to bid energy at real time or ancillary services, which could result in dynamic switching between markets to maximize profit over the course of the hour. Without the transparency of an open market, however, it would be difficult for providers to perceive the value of ancillary services and make strategic business and investment decisions.

The situation in the WECC is quite different. With the exception of California and the Canadian province of Alberta, transparent markets for energy and ancillary services are nonexistent. The power system in this landscape adheres to the traditional model, where electricity supply is essentially a monopoly service. Vertically integrated utilities, which sell approximately $60 \%$ of electricity nationally, own and operate the generation, transmission, distribution, and other facilities necessary to provide electricity service to their footprint territories in a bundled package at rates set by state public utility commissions. The most critical assets of these vertically integrated systems are owned by a single entity and profitability is limited by economic regulation. State public utility commissions set rates according to the "cost of service," which includes operating expenses as well as a reasonable rate of return on invested utility assets (or ratebase).

Like operators in organized energy markets, operators in the WECC utilize frequency regulation, load-following, operating reserves, and contingency reserves to ensure system reliability. However, in the absence of an organized market, the balancing authorities in which the vertically integrated investor owned utilities (IOUs) reside provide the ancillary services at prices governed by FERC tariffs. Even in instances where utilities procure ancillary services from outside of their own systems, the details of these bilateral transactions (including prices) are known only to the buyer and seller. 
The WECC is changing, but in ways different from the ISO/RTO regions. A series of federal and state laws and regulations throughout the past 40 years have modified the traditional model to promote new generation resources from independent power producers, provide open and nondiscriminatory access to utility transmission assets, and encourage a competitive wholesale market among vertically integrated utilities, independent power producers, and federally owned power marketing agencies. ${ }^{3}$ Despite these efforts to remove barriers to competitive wholesale-market behavior, transparent and robust wholesale energy and ancillary service markets have not emerged in the WECC. High barriers to entry in these opaque wholesale markets, coupled with the choice of western states not to liberalize retail electricity markets, have to date precluded significant investment or market entry by all but incumbent stakeholders. To sell their power, new, independently owned power plants, must secure a power purchasing agreement with an existing utility and, once secured, the power plant becomes a de facto component of that utility's vertically integrated system.

This analysis should not necessarily be read as critical of the state of the Western power system's structure and governance. Indeed, the western system has worked relatively well for the last 100 years. That is to say, it has succeeded over the long run in providing the region with low-cost, reliable electricity to consumers, and has done so despite an enormous geographical footprint and relatively low population density. Power stakeholders have evolved in the West to operate quite effectively in its opaque environment, and the WECC has developed impressive governance mechanisms that encourage cooperation and coordination in transmission planning, system expansion, and reliability assurance. Though not as integrated, open, or transparent as ISO/RTO regions, the WECC's governance structures aim toward many of the same broad goals

\footnotetext{
${ }^{3}$ See Public Utility Regulatory Policies Act of 1978, Energy Policy Act of 1992, and the Energy Policy Act of 2005, respectively.
} 
of system efficiency, reliability, and security, albeit in a distinctly "western" fashion. This distinction is not lost on the stakeholders themselves, who have crafted a shared regional identity and a palpable reticence toward federal interference with regional affairs. Today, western grid operators are tasked with integrating increasing penetrations of renewable energy onto the grid. How well these operators can coordinate their efforts and streamline the sale of ancillary services to "buffer" the variability and uncertainty of renewable generation will depend largely on the solutions they form.

\subsection{EMERGING NEEDS}

Like the U.S. as a whole, the western electricity sector is currently experiencing unprecedented growth in renewable energy supplies. This is partially due to renewable portfolio standards (state targets or goals to increase electricity generation from renewable resources) in the majority of western states. Many of the current suppliers derive these resources from wind and solar sources that are both variable and uncertain, meaning that the availability of the resource is subject to change unpredictably across multiple timescales. These characteristics necessitate innovative solutions so that system operators can maintain a reliable electricity grid, especially since standard ancillary service markets were not originally designed to accommodate variable renewable resources.

Any discussion of integrating renewable energy must also take into account the recent boon in supply of domestic natural gas. The surge of natural gas development, enabled by technological advances such as horizontal drilling and hydraulic fracturing, has created an unforeseen transformation in the energy sector; natural gas is now often cheaper than coal when used for electricity generation. Furthermore, the extensive amount of domestically recoverable 
gas intimates that there may be enough supplies to satiate current consumption levels for decades to come.

On one hand, there is a reasonable concern that renewable energy, when adding integration costs, cannot compete with cheap and abundant natural gas. On the other, it is also possible for natural gas to leverage, rather than compete with, the use of renewable resources. Renewable resources can act as a hedge against volatility in natural gas fuel prices. Furthermore, because natural gas generators are controllable, conventional, and flexible, they can respond to the variability and uncertainty of renewable energy resources more effectively than other thermal generators and thus lower renewable integration costs.

Likewise, the ability of smart-grid technologies to balance variable generation will require market pathways in order to achieve commercial scale. Demand response, which is enabled by smart grid technology, sends dynamic price signals to end users about power system needs, allowing customers to benefit from curtailing or shifting load during periods of peak demand. Power-system operators can utilize demand response, along with other smart-grid technologies, to more effectively balance supply and demand on a real-time basis. Given rising penetrations of renewable energy onto the grid, regulators will need to address incentives and disincentives in order to optimize the use of demand response as a resource.

While it is impossible to predict with certainty how the integration of higher penetrations of variable generation will impact the power grid, it is clear that a comprehensive and adaptable portfolio of approaches and solutions will be necessary to address the many potential scenarios. How stakeholders will manage renewable portfolio standards, the boon of commercially available natural gas, and technology-enabled demand response are thus important 
considerations moving forward, particularly in conjunction with the potential development of energy and ancillary service markets.

\subsection{POTENTIAL MARKET SOLUTIONS}

Present day approaches to addressing the need to integrate higher penetrations of variable generation take place on both the federal and regional levels. Specifically, western stakeholders have explored a number of market options and configurations, while the FERC has issued two Final Rules aimed at streamlining the sale of ancillary services and scheduling.

Proposed western solutions to the technical challenges of the next-generation power grid are understandably different from the organized energy market solutions that have emerged in the remaining two thirds of the U.S. WECC stakeholders are presently discussing the creation of one or several regional EIMs that could provide the system-wide efficiencies of a real-time balancing energy market without the adoption of a fully transparent energy market structure or open-access forward markets like those used in the ISO regions. At present, incumbent utilities or federally owned power marketing agencies schedule power flows without the use of fully developed markets, and many balancing authorities operate in a relatively isolated fashion. Transactions between utilities are bilateral, contractual, and long-term, and some serve providers that are unwilling to move to open markets for scheduling. However, as the WECC's power producers integrate increasing penetrations of renewable energy and pay the potentially rising costs of balancing these variable resources in real-time with local generation assets, many are interested in procuring balancing energy across a larger geographic footprint, which should lower balancing costs for the system overall. A voluntary EIM market would allow balancing authorities to procure real-time energy from the lowest-cost generator within the EIM footprint, effectively aggregating variability from both load and renewable generation across multiple 
balancing authorities. The Enhanced Curtailment Calculator, discussed in further detail in Section VI, would ensure that transmission is not curtailed by the EIM. Theoretically, the EIM and curtailment calculator should both lower the cost of balancing energy and mitigate the rising need for other ancillary services, such as providing operating reserves. The lack of a central transmission-operations entity in the West has raised novel challenges to this effort, which we discuss later.

Federal regulators have also been involved in the changing nature of the WECC's markets, as evidenced by FERC's July 18, 2013 Order 784 on the sale of third-party ancillary services at market-based rates in non-organized markets (FERC, 2012a) and FERC Order 764, the Final Rule on the integration of variable energy resources (FERC, 2012b). These two policies are intended to work together to provide for more robust ancillary service markets and improve scheduling and operations related to the integration of variable energy resources, thus mitigating the growing need for additional ancillary services (FERC, 2012c). We will discuss each in turn.

Order 784 aims to improve the ways in which parties outside of organized energy markets sell energy and capacity. FERC first acknowledged the need for power products to support transmission service in Order 888 (1996), labeling these products "ancillary services." At the outset, FERC required transmission providers to offer ancillary services to their generatorcustomers at cost-based rates. The commission was reluctant to permit market-based rates, fearing that the specialized character of these products would thwart cultivation of a competitive market. However, FERC also recognized that sales at market-based rates were permissible if the transmission provider could prove that it lacked market power in the relevant market and could 
not therefore hinder competition. To this end, FERC's Avista policy ${ }^{4}$ (1999) allowed the sale of ancillary services at market-based rates except in three situations. ${ }^{5}$ Since then, FERC has recognized that five of the seven RTOs and ISOs (NYISO, ISO-NE, PJM, MISO, and CAISO) have established sufficiently competitive markets for the majority of their ancillary services and may therefore sell those products at market-based rates. Ancillary service sales outside of the organized energy markets, however, generally have remained at cost-based rates because transmission providers have found it too difficult to prove they lack market power. FERC Order No. 784 revises the now decade-old Avista policy by narrowing restrictions on ancillary service sales outside of organized energy markets. Specifically, the rule provides for numerous ways by which transmission providers outside of the five approved RTO or ISO markets may demonstrate their lack of market power and therefore justify sales at market-based rates.

Order 764 concerning the variable energy resources rule is of a different tenor than Order 784. Rather than allowing greater flexibility in operations and transactions, it calls on FERC's federal regulatory powers to mandate uniform scheduling requirements for transmission providers and enhanced forecasting data requirements for renewable energy providers. Specifically, transmission operators must offer transmission service scheduling to their generation customers on a 15-minute basis, rather than the commonly adopted hourly basis. Variable energy generators, in turn, must provide transmission operators with power-production forecasting data. Although transmission providers must make intra-hour scheduling available to their customers, their customers are not required to request or utilize it. Thus, the practical effect

\footnotetext{
${ }^{4}$ See 87 FERC $₫ 61,223$ (Avista), order on reh’g, 89 FERC \ 61,136 (1999).

${ }^{5}$ These situations include sales to an RTO or ISO, sales to an affiliated franchised public utility, and sales to transmission providers who offer their services to transmission customers under their tariffs.
} 
of Order 764 on scheduling depends on whether transmission customers avail themselves of more frequent scheduling.

These developments from both within and outside the WECC are critical to other markets in the West, as they lay both the technical and policy groundwork for further market development while, conversely, potentially reduce the need for ancillary services by improving the interconnectedness, efficiency, and reliability of the system. Equally important, the WECC EIM discussions have revealed a number of stakeholder dynamics that are likely to recur as the Western Interconnection continues to evolve. Central to these and emerging efforts, is the need to reconcile the West's unique governance structures, which favor more autonomous balancing authority operations and protect proprietary power system information from dissemination to other stakeholders or competitors, with the potential economic benefits of more coordinated system operations over a larger geographical footprint. In the next section, we examine some of the barriers to market development for the western electricity system and how these barriers might impede further evolution within the WECC region, particularly with regard to energy and ancillary services markets.

\subsection{BARRIERS TO ENERGY AND ANCILLARY SERVICE MARKETS}

Structural measures, particularly markets, to accommodate rising variable generation in the WECC face a variety of economic, socio-cultural, and technical barriers; some are clearly surmountable, while others have recurred throughout the western grid's history and admit no clear solution. We discuss several of these phenomena here, with an eye toward implications for the development of organized markets in the WECC.

\subsubsection{Market Design}


In organized energy markets, the relevant RTO or ISO manages markets for energy and ancillary services with transparent pricing and scheduling. In much of the West, however, market operators do not exist. It is thus unclear who would manage a competitive market for ancillary services in an independent and neutral fashion, and how a competitive market would be structured to prevent collusion or market abuse without an ISO or RTO entity. A natural policy question is whether the West would ever form an ISO or RTO to solve the problem. As it turns out, WECC stakeholders in both the Southwest and Northwest have engaged in multiple serious efforts to do just that, starting in the early 1990s. Though it appeared in each attempt that an RTO was achievable, none of these initiatives ever culminated in a fully operational RTO. One such effort was called Desert Southwest Transmission and Reliability Operator (Desert STAR), which included Arizona, New Mexico, northern Nevada, eastern Wyoming, Colorado, and West Texas (Kirkland \& Ellis, 2002). Desert STAR ultimately evolved into WestConnect, a for-profit, investor-owned transmission planning and coordination entity referred to as a "Transco." In the Pacific Northwest, extensive endeavors to form an RTO also took place, though none have yet come to fruition. The earliest iteration was the Independent Grid Operator (IndeGO), which was reincarnated as RTO West in 2000, then Grid West in 2003. Ultimately, the effort resulted in ColumbiaGrid in 2006, a non-profit transmission planning organization that did not provide market operations. Thus, in spite of multiple genuine efforts, a western RTO (outside of California or Alberta) has never fully materialized. This may be due to the fact that the West never had the coordinated power pools that the East had back in the 1960s as a starting point for market development. In any event, it bears pondering whether anything has changed that would result in a different outcome today. 
In the absence of an independent market operator, management of ancillary service markets through bid acceptance, dispatch order, and payment reconciliation might fall, as suggested by the WECC EIM proposal, to an RTO based outside of the non-restructured regions of WECC (namely the Southwest Power Pool or the CAISO). Alternately, large transmission owners might operate their own ancillary service markets and allow other balancing authorities to bid into it, taking advantage of the market liberalization proposed in FERC Order 888. But with the shape of the EIM unknown at present, the market-design question suffers from a classic chicken-and-egg problem; without system-wide ancillary service pricing and valuation data and certainty with respect to market structure and transmission costs, participants cannot calculate the costs and benefits of participation, and thus are reticent to create the market.

\subsubsection{Cost-Allocation and Transmission Rights}

The transmission of ancillary services from generators to the areas where power is needed is an important consideration raising numerous cost-allocation problems, particularly where ancillary services might be sourced in one location in order to remedy grid problems in another location. In such cases, how are transmission rights allocated and who pays the actual cost of new transmission capacity? These challenges are presently apparent in the WECC's recent efforts to form an EIM. Effectively implementing an EIM requires substantial support and participation among western balancing authorities. Reaching "critical mass," so to speak, entails a host of considerations, including governance, market operation, financing, and exit provisions. A vital one is the composition of the EIM footprint and, by proxy, the extent of the gains and losses for participants. While balancing authority participation does not necessarily have to be contiguous, non-contiguous operations between participants and non-participants will 
increase problems across the seams (inefficiencies that prevent the economic transfer of capacity and energy among control areas) and necessitate greater coordination.

The ultimate success of the EIM therefore could strongly depend on which stakeholders choose to participate. Any such calculation will have to consider the Bonneville Power Administration (Bonneville) and its extensive transmission assets. Bonneville owns threefourths of the Pacific Northwest's transmission, and its assets are interwoven among the remaining quarter. It would therefore be difficult to implement a western EIM without Bonneville's participation. However, pursuant to a benefits analysis conducted by the NREL, Bonneville is expected to suffer high implementation and operating costs should it participate in the EIM, while a preponderance of other western stakeholders stand to benefit (Milligan, et al., 2013). Under any choice going forward, Bonneville will likely require assurances. A successful EIM proposal, then, will almost certainly demonstrate how Bonneville and its preferential public-power customers will profit or, at the very least, will not suffer any financial losses.

\subsubsection{Western Culture}

The utilities of the western power grid possess numerous idiosyncrasies that distinguish them from the rest of the country and have played a large role in regional decision-making. These idiosyncrasies can be characterized by ambivalence about markets (particularly organized energy markets) and a firm adherence to the notion that the West is unique and requires specialized treatment. To predict future market developments with any certainty, it would be prudent to consider the western culture in that calculation.

The market aspect of the western culture is perhaps most attributable to a number of events that took place in the past two decades. The history of the electricity sector in the West has been influenced by a number of important events and powerful stakeholders, the combination 
of which has thwarted the development of any foreseeable western organized energy market and subsequent ancillary service market. Two factors in particular, the California Energy Crisis in the early 2000s and the multiple attempts to form a western RTO, have played a considerable role in the current state of the western stakeholder mindset.

The California Energy Crisis had far-reaching implications for the rest of the nation's electricity sector, especially for the western power grid. In the early 1990s, costly nuclear power investments and high-priced contracts for Qualifying Facility power led to sharp increases in California's electricity prices (Weare, 2003). California's response was to explore the possibility of deregulating and restructuring its electricity sector. In 1996, after months of hearings facilitated by the California Public Utility Commission, the state's legislature drafted and passed AB 1890, its "blueprint" proposal for electricity deregulation. The central goal was to break up the three dominant vertically integrated IOUs in order to create competitive markets for both generation and retail marketing (Weare, 2003). To this end, the proposal called for the formation of the California ISO (CAISO) to assume control of the transmission grid. Like other ISO/RTOs, CAISO's purpose was to manage dispatch throughout the grid in a nondiscriminatory manner (such that every generator had equal access) and ensure system reliability. Unlike other ISO/RTOs, the competitive retail market would be facilitated by an entirely different entity. The Power Exchange, separate from CAISO, would auction generated power in hour-ahead and dayahead markets (Weare, 2003).

Starting in the late spring of 2000 , electricity prices for wholesale power in California rose exponentially. This was compounded by regional rolling blackouts, the costs of which were not insignificant. The consequences were catastrophic: the three main IOUs were driven into severe debts, the Power Exchange went bankrupt and was forced to shut down, and CAISO was 
targeted for its failure to adequately manage the grid (Weare, 2003). Most analysts agree that California's market design was a significant cause of the energy crisis (Weare, 2003).

Hard lessons were learned from California, and it caused the rest of the West to reconsider state restructuring and deregulation initiatives. California's market design exposed the very real and severe risks of forming an organized energy market. In response to the energy crisis, the state's voters recalled Governor Gray Davis, sending a powerful political message to other western leaders. California' experience undoubtedly decelerated or suspended efforts to develop western power markets for the next ten or so years.

As noted above, western stakeholders worked extensively on numerous iterations of an organized energy market between the early 1990s and mid-2000s. The diversity of western stakeholders, uncertainty about costs, reluctance to abdicate transmission rights, doubt regarding market benefits, and a slew of other factors contributed to the downfall of these efforts. Nonetheless, Desert STAR and Grid West ultimately culminated in transmission planning organizations that function today. However, the emergence of western transmission planning organizations may obscure the fact that a western RTO was never fully implemented outside of California. It appears that repeated but unsuccessful attempts to form a western RTO continued to shape stakeholder hesitations about markets for energy and ancillary services today.

The other facet of the Western culture pertains to the uniqueness of the West, geographically, socially, and grid-wise. Geographically, the West is certainly distinctive; major generation sources are often remote relative to load centers, large distances separate load centers, and half of total hydropower generation capacity is located in California, Oregon, and Washington (EIA, 2011). These features are particularly relevant when it comes to transmission planning and siting, and signifies the potential need for (some) new transmission capacity to 
wheel power from resources to the market. Compounding this reality, however, is the western disfavor of federal oversight. For many, if not all, of the RTO iterations, submitting to FERC jurisdiction was a genuine stakeholder concern. The West is a historically autonomous region, largely viewing itself as free from East Coast politics and control; this mindset, coupled with the scars of several attempts to organize, has generated grid market gridlock.

\subsection{NON-MARKET ALTERNATIVE SOLUTIONS}

In lieu of an EIM or some other market mechanism, western stakeholders are pursuing non-market (or pseudo-market) solutions to the variable generation integration (ancillary service) issue. Informing these solutions is the belief that reliability can be achieved through enhanced cooperation among western stakeholders. To that end, three regional transmission provider groups, WestConnect, ColumbiaGrid, and Northern Tier Transmission Group, are engaged in a joint initiative to address regional transmission challenges in a collaborative manner. Their panoply of operational solutions outside of the EIM includes the Intra-hour Transaction Accelerator Platform (ITAP), the Dynamic Scheduling System (DSS), Balancing Authority Reliability-based Control (RBC), and Area Control Error (ACE) Diversity Interchange (ADI). ITAP is a computer-based tool that facilitates bilateral intra-hour energy transactions. A webbased system, it allows users to bid, purchase, and sell energy in a single, user-friendly forum. Similarly, the DSS is a communications infrastructure designed to allow participants to establish links between balancing authorities on a transaction-by-transaction basis at any level of granularity.

Two other tools, RBC and ADI, are particularly helpful for balancing authorities. Area control error is a measure of a given balancing authority's load and generation imbalance. ADI serves to electronically balance load and generation among several balancing authorities by 
exchanging the area control error requirement of over-generating authorities with that of the under-generating authorities. With this tool, balancing authorities can integrate higher penetrations of variable generation within a larger pool. Likewise, RBC is a proposed replacement for Control Performance Standard 2, which proscribes area control error limits as mandated by NERC. RBC would serve to relax these limits when the Western Interconnection as a whole is well balanced. Together, these mechanisms facilitate the exchange of energy efficiently over larger regions and at shorter timescales.

Reserve sharing groups are another non-market alternative to a regional EIM. As noted above, power-system reserves are continuously available quantities of generation or demand to maintain system reliability. Reserve sharing groups consist of two or more balancing authorities that together maintain and supply operating reserves to be used in the event of a contingency within the group. By expanding a single balancing authority's footprint across multiple balancing authorities, unforeseen fluctuations are averaged out within the broadened area. This function is especially essential to address the variability and uncertainty of renewable generation, including extreme events when wind output drops quickly without warning.

Finally, the Enhanced Curtailment Calculator would manage power-flow impacts across seams within the entire WECC footprint. As a seams coordination tool, the curtailment calculator's purpose is to coordinate transmission curtailments and provide the Reliability Coordinator better information about transmission loading in order to ensure system reliability. While the curtailment calculator is capable of operating independently, it can also work in conjunction with an EIM to make certain that transmission is not curtailed by the EIM; that is, traditional reserved transmission would always take precedent over EIM dispatch. 
Each of these alternative solutions can be seen as potentially effective, yet provisional repairs to a very complex problem for the western power grid. Today, it is unclear whether these solutions, individually and taken together, could attend to the challenge of integrating higher penetrations of renewable energy resources over the long term.

\section{CONCLUSION}

While no region in the United States is impervious to the reliability and economic concerns that accompany the integration of renewable energy, the Western Interconnection, for all of its geographical, political, technical, and sociological idiosyncrasies, is in a unique position compared to its Eastern and Texan counterparts. It remains unclear whether solutions implemented elsewhere are right for the West. If a great deal of weight is given to the barriers discussed above (the western market design, cost-allocation and transmission rights, the western culture, and the abundance of balancing authorities given the West's geographic and demographic characteristics) perhaps not all ISO/TRO approaches to renewable integration and system reliability are practical here. If so, what are the potential solutions? The WECC's current incremental responses to these issues may soon become inadequate. Stakeholders are likely to repeatedly confront the possibility of forming a market, whether an EIM, a full-fledged RTO with associated ancillary service markets, or even a kind of independent ancillary-service market without the RTO super-structure.

There is good reason for policy-makers to become more involved in this discussion, and to take a leadership role in doing so. Integration concerns are no longer a purely internal concern of the entities that run the power grid. Rather, these issues have broad-ranging effects, from the growth of the renewable energy industry to climate and environmental impacts. Moreover, existing grid stakeholders may not adequately represent the full range of interests. Finally, some 
barriers to progress may be so entrenched as to require legislative solutions. Specific recommendations about these modifications are beyond the scope of this analysis, but a higherlevel discussion in the policy space is required if the western grid is to evolve in a manner that ultimately serves the needs of the region and the nation.

\section{ACKNOWLEDGMENTS}

The authors acknowledge the support of the Joint Institute for Strategic Energy Analysis, which is operated by the Alliance for Sustainable Energy, LLC, on behalf of the U.S. Department of Energy's National Renewable Energy Laboratory, the University of Colorado-Boulder, the Colorado School of Mines, the Colorado State University, the Massachusetts Institute of Technology, and Stanford University.

\section{REFERENCES}

Bohne, E. (2011). "Conflicts between national regulatory cultures and EU energy regulations." Utilities Policy, Vol. 19, pp. 255-269.

Cappers, P.; Macdonald, J.; Goldman, C.; Ma, O. (2013). “An assessment of market and policy barriers for demand response providing ancillary services in U.S. electricity markets.” Energy Policy, Vol. 62, pp. 1031-1039.

DeCesaro, J. and Porter, K. (December 2009). "Wind Energy and Power System Operations: A Review of Wind Integration Studies to Date." NREL/SR-550-47256. Golden, CO: National Renewable Energy Laboratory. http://www.nrel.gov/docs/fy10osti/47256.pdf

EIA. (2011). "Hydropower has a long history in the United States.” Today in Energy. Washington, D.C.: U.S. Energy Information Administration. http://www.eia.gov/todayinenergy/detail.cfm?id=2130.

Ela, E.; Milligan, M.; and Kirby, B. (August 2011). "Operating Reserves and Variable Generation.” NREL/TP-5500-51978. Golden, CO: National Renewable Energy Laboratory. http://www.nrel.gov/docs/fy11osti/51978.pdf

Ela, E.; Kirby, B.; Navid, N.; and Smith, J.C. (2012). "Effective ancillary service market designs on high wind power penetration systems." In proceedings Power and Energy Society General Meeting, July 2012. 
Federal Energy Regulatory Commission. (1996). Promoting Wholesale Competition Through Open Access Non-discriminatory Transmission Services by Public Utilities; Recovery of Stranded Costs by Public Utilities and Transmitting Utilities. Order No. 888. (April 1996.) Accessed April 2014 at http://www.ferc.gov/legal/maj-ord-reg/land-docs/order888.asp.

Federal Energy Regulatory Commission. (2012a). Third-Party Provision of Ancillary Services; Accounting and Financial Reporting for New Electric Storage Technologies. 139 FERC 61,245 (June 22, 2012). Accessed April 2014 at http://www.ferc.gov/whats-new/commmeet/2012/062112/E-2.pdf.

Federal Energy Regulatory Commission. (2012b). Integration of Variable Energy Resources. 139 FERC 61,246 (June 22, 2012). Accessed April 2014 at http://www.ferc.gov/whatsnew/comm-meet/2012/062112/E-3.pdf.

Federal Energy Regulatory Commission. (2012c). "Statement of Commissioner John R. Norris on Variable Energy Resources Final Rule and Notice of Proposed Rulemaking on Ancillary Services and Storage Technologies." (June 21, 2012.) Accessed April 2014 at http://www.ferc.gov/EventCalendar/Files/20120622073119-E-2-3-NORRIS.pdf

Kirkland \& Ellis (October 2002). "Declatory Order on Regional Transmission Organization." WestConnect RTO, LLC, Volume II, Issue VIII.

Milligan, M.; Clark, K.; King, J.; Kirby, B.; Guo, T.; Liu, G. (March 2013). "Examination of Potential Benefits of an Energy Imbalance Market in the Western Interconnection." NREL/TP5500-57115. Golden, CO: National Renewable Energy Laboratory. http://www.nrel.gov/docs/fy13osti/57115.pdf

Sovacool, B. (2009). "The intermittency of wind, solar, and renewable electricity generators: Technical barrier or rhetorical excuse?" Utilities Policy, Vol. 17, pp. 288-296.

Weare, C. (2003). "The California Electricity Crisis: Causes and Policy Options." San Francisco, CA: Public Policy Institute of California.

http://www.ppic.org/content/pubs/report/R_103CWR.pdf 